\title{
«Psalm» of the Doukhobors Javakheti «Uzrekh Mnogo Narodu» \\ as a Typical Example of the Genre
}

\author{
Alexandra V. Kosykh* \\ St. Petersburg State Rimsky-Korsakov Conservatory \\ St. Petersburg, Russian Federation
}

Received 10.10.2021, received in revised form 10.12.2021, accepted 18.01.2022

\begin{abstract}
Psalm «Uzrekh mnogo narodu» is the most important in the liturgical and funeral practices of the Doukhobors of Javakheti. Its text, containing nine Evangelical Beatitudes, borrowed from the Orthodox Typicon, conveys the most important Christian values, which observance helps to achieve the Heavenly Kingdom. The features of musical style of the psalm (composition, scale, intonation, rhythmic) are characteristic also of other samples of a genre. The musical stanzas are of considerable length. The composition is characterized by the complexity of the principles of coordination of poetic text and melody. The wide chant of syllables is one of the genre and style features. In the development of the tune, the trichord musical phrase (a-c1-d1) plays a leading role, which varies and repeats many times. The question of the origin of the Dukhobor psalm genre is still open, but its links with Orthodox culture at the level of texts and of principles of inclusion in ritual, at the level of tune with narrative genres of musical folklore are obvious.
\end{abstract}

Keywords: doukhobors, a sect, psalms, Living book of the doukhobors, religious songs, folklore.

Research area: philosophy and history of religion, philosophical anthropology, philosophy of culture

Citation: Kosykh, A.V. (2022). «Psalm» of the doukhobors Javakheti «Uzrekh mnogo narodu» as a typical example of the genre. J. Sib. Fed. Univ. Humanit. soc. sci., 15(1), 48-60. DOI: 10.17516/1997$1370-0875$

(C) Siberian Federal University. All rights reserved

* Corresponding author E-mail address: akseniya.krupkina@mail.ru 


\title{
«Псалом» духоборцев Джавахетии «Узрех много народу» как характерный пример жанра
}

\author{
А.В. Косых \\ Санкт-Петербургская государственная консерватория \\ им. Н.А. Римского-Корсакова \\ Российская Федерачия, Санкт-Петербург
}

\begin{abstract}
Аннотация: Псалом «Узрех много народу» является важнейшим в богомолебной и похоронно-поминальной практике духоборцев Джавахетии. Его текст, содержащий девять евангельских заповедей блаженства и заимствованный из православного Типикона, транслирует важнейшие христианские ценности, соблюдение которых помогает достичь Небесного Царствия. Особенности музыкального стиля псалма «Узрех много народу» (композиционные, ладовые, интонационные, ритмические) характерны и для других образцов жанра. Музыкальные строфы напева отличаются значительной протяженностью. Композиция песнопения характеризуется сложностью принципов координации поэтического текста и напева. Широкораспевность является одним из жанрово-стилевых признаков. В развитии напева ведущую роль играет трихордовая попевка (a-c $\left.\mathrm{c}^{1} \mathrm{~d}^{1}\right)$, которая варьируется и многократно повторяется. Вопрос происхождения жанра духоборческого псалма пока остается открытым, но очевидны его связи с православной культурой на уровне текстов и включения в обрядность на уровне напевов с повествовательными жанрами музыкального фольклора.
\end{abstract}

Ключевые слова: духоборцы, секта, псалмы, Животная книга, религиозные песнопения, фольклор.

Научная специальность: 09.00.13 - философия и история религии, философская антропология, философия культуры

\section{Введение в проблему исследования}

Духоборцы - представители христианской секты, сложившейся в XVIII столетии преимущественно из числа однодворцев и служивого населения южных губерний Российской империи. Духоборцы переняли западные представления о внутреннем откровении Бога в человеке, переосмыслив их в хлыстовском духе, предполагая возможность боговоплощения в лице духовного лидера секты: кроме того, они предельно упростили религиозные обряды, отказались от духовенства, культовой литературы, религиозной атрибутики, не почитают святых (за исключением своих собственных покойных религиозных лидеров). В начале XIX в. духоборцы получили возможность компактного проживания на территории Мелитопольского уезда Таврической губер- нии, откуда в 1840-х гг. были высланы в Закавказье. Вследствие внутреннего раскола, произошедшего в 1890-х гг., значительная часть сектантов эмигрировала в Канаду. В различные периоды XX в. закавказские духоборцы переселялись на территорию современной России. В настоящее время крупные духоборческие общины продолжают существовать в Грузии, Канаде и России.

Вероучение духоборцев базируется на текстах и песнопениях, называемых псалмами. ${ }^{1}$ Традиционно псалмы хранятся в памяти представителей духоборче-

1 В настоящем исследовании термином «псалом» называется религиозное духоборческое песнопение (или читаемый особым образом текст), источником которого, в отличие от жанра молитвословной поэзии, не всегда является «Псалтырь». Псалмы духоборцев хранятся в памяти и передаются устно. В подобном значении термин 
ских общин, в совокупности составляя так называемую «Животную книгу», написанную «во сердцах» и передающуюся устно из поколения в поколение. ${ }^{2}$ Многие тексты обнаруживают первоисточники в Священном писании и другой христианской литературе, а также в фольклорных или «книжных» духовных песнопениях. Часть псалмов представляют оригинальные духоборческие произведения, среди которых выделяются тексты, составленные наподобие катехизиса - в форме вопросов и ответов.

Псалмы функционируют в основном во время богомолений (которые совершаются по воскресеньям и в дни христианских праздников) и в похороннопоминальном обряде. Моление духоборцев (которое они называют «поклонение») можно условно разделить на три части. Сначала мужчины и женщины, сидящие друг напротив друга, по очереди произносят тексты различных псалмов в определенной интонационно-метрической манеpe. После этого они запевают какой-либо псалом (как правило, соответствующий по содержанию тематике религиозного праздника). Во время пения духоборцы совершают ритуальные поклонения образу Божьему друг в друге - «видаются». Текст пропетого псалма прочитывается одним из молящихся от начала до конца, завершаясь устойчивой конечной формулой «Богу нашему слава». В заключение богомоления духоборцы поминают усопших родственников, при этом также поется какой-либо псалом (Kosyh, 2018). Пение псалмов играет важную роль в похоронно-поминальном обряде: установленный традицией порядок исполнения напевов структурирует его ход, а содержательная часть текстов «псалмов» последовательно отражает религиозные представления, связанные с загробной жизнью (Inikova, 2018). Псалмы читают и поют на протяжении всего обряда: при

используется в работах Черткова (1910), Рудиченко (1990), Зернина (2017).

2 В начале ХХ в. В.Д. Бонч-Бруевич издал «Животную книгу духоборцев», в которую вошло более 300 текстов (в основном псалмов) (Бонч-Бруевич, 1909). положении в гроб, во время сидения над покойным, при прощании с умершим, при выносе гроба, по дороге на кладбище, при опускании гроба в могилу, при возвращении с кладбища, на поминальных трапезах.

Напевы псалмов исполняют «певчие» мужчины и женщины из общины, одаренные музыкально. Данные песнопения имеют гетерофонную фактуру с элементами дифференцированного двухголосия и звучат в октавном удвоении. Напевы псалмов характеризуются сложностью композиции и развитостью музыкальных построений, лежащих в ее основе. С одной стороны, «бесконечность» духоборческих псалмов позволяет исполнителям погрузиться в особое серьезное и сосредоточенное молитвенное состояние, соответствующее представлениям о внутреннем откровении Бога в человеке. С другой стороны, многораспевность выполняет прагматические функции, поскольку сопровождает различные обрядовые действия, имеющие значительную протяженность во времени.

Согласно комментариям народных исполнителей, напевы состоят из «взводов», членящихся на «колена», которые нужно «где-то опустить, а где-то поднять» ${ }^{3}$. В результате сопоставления народной и этномузыковедческой терминологии можно установить следующее соотношение: «взвод», являющийся композиционной единицей псалмов, соответствует музыкальнопоэтической строфе; составляющие его «колена» - это попевки или попевочные комплексы, образующие напев. Следует отметить, что не все псалмы имеют напевы, некоторые бытуют только в форме чтения. Это может быть связано с тем, что часть мелодий предана забвению, а часть, возможно, никогда не распевалась.

\section{Методология и материалы исследования}

Более ста лет исследователи обращаются к текстам и напевам псалмов духобор-

\footnotetext{
3 Архив ФЭЦ СПбГК. ОЦФ № 276-002-004-36, с. Архангельское Чернского р-на Тульской обл. Записала Шатилина (Косых) А. В. от Батуриной Пелагеи Федоровны 1947 г. p.
} 
цев. Как правило, описывая особенности данных форм, ученые выходят за рамки главной сферы своих научных интересов: религиоведческие работы включают этнографические замечания (Bonch-Bruevich, 1909) и наоборот (Inikova, 2018); музыковедческие исследования соприкасаются с вопросами специфики поэтических текстов и особенностями бытования псалмов в духоборческих традициях (Chertkova, 1910, Linyova, 2002, Rudichenko, 1990, Zernina, 2017). Подобный подход к жанру обусловлен его спецификой, сходной с особенностями фольклорных текстов: псалмы неразрывно связаны с религиозными ритуалами и обрядами жизненного цикла, их поэтические тексты и напевы отражают представления о мироустройстве; псалмы передаются изустно, допускается варьирование текстов и напевов, песнопения не имеют авторства, многие тексты являются фольклорными по происхождению. Исследовательские работы, посвященные псалмам, как правило, либо раскрывают отдельные свойства данного жанра, либо обладают высокой степенью обобщенности в их характеристике, не позволяющей проследить особенности всех элементов на конкретных примерах.

Настоящая статья опирается на метод комплексного анализа, что предполагает выявление контекста исполнения псалма, его функций, происхождения и специфики поэтического текста, характеристику стилевых свойств напева. Эти аспекты позволят продемонстрировать характерные признаки жанра на примере одного образца.

Для рассмотрения выбран важнейший духоборческий псалом «Узрех много народу» (или «Узрех», как называют его духоборцы), в тексте которого содержится девять евангельских заповедей блаженства. Данное песнопение бытует в традициях общин, проживающих на различных территориях, и обладает высокой обрядовой значимостью. В одном из катехизических текстов, опубликованных В.Д. Бонч-Бруевичем в «Животной книге духоборцев», интересующий нас псалом фигурирует как молитва, обязательная для религиозных собраний:
«29. Вопрос: Какие молитвы имеете в собрании своем?

Ответ: Во-первых, псалом «живые в помощь вышнего, в кров Бога небесного...»; второе: «услыши, Господи, глас мой, егда молимся Тебе...»; третье: «девять блаженств» из Евангелия, с прибавлением: «помяни нас, Господи, егда придеши в царствие Свое ${ }^{4} \gg$ (Bonch-Bruevich, 1909: 20).

Согласно легенде, опубликованной С.А. Иниковой, «Узрех» является первым духоборческим псалмом, который «вложил в уста» лидеру секты Илариону Побирохину его «духовный отец» (Inikova, 1997: 40).

Материалами исследования послужили варианты псалма «Узрех много народу», записанные С.Е. Никитиной в 1985 г. от жителей г. Богдановка Богдановского p-на Грузинской ССР. ${ }^{5}$ Кроме того, учитываются сведения, полученные автором данного исследования в рамках фольклорноэтнографической экспедиции 2011 г. в с. Архангельское Чернского р-на Тульской обл., где проживают переселенцы из с. Гореловка Богдановского р-на Грузии. ${ }^{6}$

\section{Контекст исполнения}

В духоборческих традициях псалом «Узрех» функционирует в нескольких формах: как «читающийся» текст, как комбинация песнопения и чтения и как песнопение.

Текст псалма «Узрех» может быть прочитан в первой части любого духоборческого моления. В рамках религиозных собраний на Рождество или Пасху (в даты особо значимых христианских праздников) духоборцы поют псалом «Узрех»: мужчины и женщины, сидевшие рядами друг

\footnotetext{
4 Здесь и далее в текстах из «Животной книги духоборцев» сохранена орфография автора.

5 Архив ФЭЦ СПбГК ОФК-035-Кассета 03-12. г. Богдановка Богдановского p-на Грузинской ССР. Записала С.Е. Никитина от М.С. Юрицыной 1922 г. p. (пение); Архив ФЭЦ СПбГК ОФК-035-Кассета 02-13, г. Богдановка Богдановского p-на Грузинской ССР. Записала С.Е. Никитина от жителей г. Богдановка (пение, чтение).

6 Архив ФЭЦ СПбГК ОЦФ № 276 с. Архангельское Чернского р-на Тульской обл. Записала А.В. Косых от переселенцев из с. Гореловка Богдановского р-на Грузии.
} 
напротив друга, встают и исполняют первый «взвод». Начиная со второго «взвода», они «видаются» - кланяются друг другу. Обряд начинают мужчины: второй в ряду подходит к первому, взявшись правыми руками, они делают два поясных поклона друг другу, целуются и кланяются еще раз. После этого оба поворачиваются к женщинам и отдают им четвертый поклон. Второй мужчина встает на свое место, тогда третий «видается» с первым и вторым, четвертый с первым, вторым, третьим и т. д. Когда все мужчины «повидаются», поклонения совершаются среди женщин в таком же порядке. Далее духоборцы могут пропеть еще «взвод», а затем «прочитывают» текст от начала до конца (Kosyh, 2018: 132).

На похоронах «Узрех» исполняют несколько раз: при выносе гроба со двоpa, после опускания покойного в могилу и на поминальной трапезе. По дороге на кладбище «певчие» поют три «взвода» «Узрех», затем запевают похоронный «стишок» «А вы голуби». На кладбище псалом поется заново, под пение гроб опускают в могилу, и «певчие», а также кто-либо из родных покойного совершают поклонения - «видаются». Пропев псалом, его текст прочитывают от начала до конца.

На поминальной трапезе певчие также поют «Узрех» и, начиная со второго взвода, «видаются» друг с другом.

Приуроченность напева «Узрех» к похоронному обряду возведена в ранг канона и закреплена в тексте вопросно-ответного псалма, опубликованного В.Д. БончБруевичем:

«31 вопрос: Когда человек помрет, что вы над ним делаете?

Ответ: Молитвы читаем.

32 вопрос: Какие?

Ответ: «Прими меня отче, к себе во грядущее...»

33 вопрос: Понесете какие псалмы поете?

Ответ: «Узрех много народа, взыду на гору» (Bonch-Bruevich, 1909: 66).

Таким образом, псалом «Узрех много народу» является одним из главных молитвенных песнопений. Он звучит в особенно важные для религиозной общины моменты как напутствие для живых и усопших.

\section{Содержание и происхождение поэтического текста}

Востребованность «псалма» «Узрех» в культуре духоборцев обусловлена его содержанием (прил. 1). Поэтический текст представляет собой близкий пересказ нагорной проповеди Иисуса Христа (Мф. 5:112), в которой называются девять евангельских блаженств, с прибавлением слов благоразумного разбойника: «Помяни мя, Господи, егда приидеши во Царствии Твоем»! (Лк. 23:42). Как отмечает С. А. Иникова, «Псалом "Узрех" - это молитва певчих о соединении души покойного с Богом», привести к которому может следование девяти заповедям (Inikova, 2018: 333-334). Духоборцы трактуют заповеди блаженства следующим образом:

«32 вопрос: Что есть девять блаженств евангельских?

Ответ: Вольная нищета, плач о грехах, крепость желанья, правда, милость, чистосердечное миротворенье, изгнание правды ради, поношения за имя Господне» (BonchBruevich, 1909: 59).

Заповеди блаженства затрагивают важнейшую для данного сообщества тему гонимости истинной веры. Религиозные представления становились поводом для ссылки и тюремного заключения духоборцев на этапе становления секты. Кроме того, в конце XIX в. они были выселены с плодородных земель Мелитопольской губернии в суровые земли Закавказья.

Несмотря на то что первоисточник псалма очевиден, данный текст, скорее всего, был заимствован не напрямую из Евангелия, а через православный богослужебный устав, на что указывает прибавление к заповедям слов благоразумного разбойника. Именно в такой форме заповеди блаженства присутствуют в последовании Изобразительных (которые иногда называют Обедницей) (Kashkin, 2010: 345). Включение данного текста в похоронно-поминальный обряд также могло быть установлено по примеру пра- 
вославных: заповеди блаженства являются частью отпевания покойного (Trebnik, 2008: 191). Следует отметить, что и другие религиозные традиции духоборцев обнаруживают связь с православием: они усвоили праздники Церковного календаря, применяют в обрядах отдельные религиозные словесные формулы, принятые в православии, кроме того, обряд богомоления является интерпретацией христианского обычая «целование мира», который в Православной Церкви в настоящее время присутствует среди сослужащих иереев (Kosyh, 2018). Тем не менее духоборцы трактуют заимствованные тексты и ритуальные действия сообразно своим религиозным представлениям, которые коренным образом отличаются от православных.

\section{Музыкально-стилевые особенности напева}

Фиксируя псалмы в начале XX столетия, А. К. Черткова отмечала, что среди них есть более или менее «красивые и оригинальные напевы» (Chertkova, 1910: 4). Сами духоборцы условно разделяют песнопения на простые и сложные. Сложные напевы состоят из большего количества «колен», простые - из меньшего. Псалом «Узрех» духоборцы относят к «трудным»: «"Узрех" поется, там каждая буковка тянется, тянется».7 Певчая Гончарова Ульяна Васильевна 1941 г. р. из с. Архангельское вспоминает день, когда она начала петь в хоре: «Я пошла в первый раз, они (певчие) "Узрех" твердили (учили). Я пришла, два дня побыла и говорю: "Ой, я ходить не буду, я ничего не понимаю"»».8

Многораспевность «взводов» некоторых псалмов провоцировала неполную фиксацию напевов. Часто исполнители демонстрировали лишь один-два «взво-

\footnotetext{
Архив ФЭЦ СПбГК. ОЦФ № 276-005-001-05, c. Архангельское Чернского р-на Тульской обл. Записала А.В. Шатилина (Косых) от Гончаровой Ульяны Васильевны 1941 г. р.

8 Архив ФЭЦ СПбГК. ОЦФ № 276-005-003-23, c. Архангельское Чернского p-на Тульской обл. Записала А.В. Шатилина (Косых) от Гончаровой Ульяны Васильевны 1941 г. р.
}

да», в результате у исследователей могло сложиться ложное впечатление о стабильности строфической организации псалмов. Музыкальная форма псалма «Узрех» отличается значительной протяженностью, в связи с чем духоборцы не распевают текст целиком, обычно исполняя три «взвода». Записи песнопения «Узрех», доступные нам, требуют реконструкции. Одна из них представляет сольный вариант первого «взвода» (прил. 2), другая же получена C.Е. Никитиной методом включенного наблюдения, и второй-третий «взводы» были зафиксированы фрагментарно. Тем не менее очевидно, что три «взвода» псалма «Узрех» не идентичны: первый членится на две сходные полустрофы. Напев несколько изменяется во втором и третьем «взводе» (за счет вариации комбинаций серединных музыкальных построений), при этом общий контур мелодии во всех «взводах» остается узнаваем. Музыкальные повторы (попевки, сходные полустрофы ${ }^{9}$ ) соотносятся со сквозным развитием поэтического текста.

В основе каждого «взвода» лежит поэтическое двустишие, которое несколько разнится с «читаемым» вариантом (табл. 1). ${ }^{10}$

Поющийся текст усложняется огласовками (как в раздельноречии у старообрядцев) и дифтонгами. Ритм произнесения слогов «растворяется» в распевах, протяженность которых неодинакова (табл. 2).

Наиболее краткие распевы приходятся на огласовки, что свидетельствует о дифференцированном применении данного художественного приема. Поэтические строки текста разного слогового состава соотносятся с музыкальными полустрофами (более стабильными по протяженности). Зоны распевов не всегда совпадают с ударными слогами текста, вследствие чего можно заключить, что напев и поэтический текст в данном псалме существуют достаточно

\footnotetext{
Сходство полустроф менее заметно в первом «взводе», в большей степени очевидно во второй и третьей строфах. ${ }^{10} \mathrm{Bce}$ таблицы и нотные примеры основаны на расшифровке псалма «Узрех», приведенного в прил. 2 (Архив ФЭЦ СПбГК ОФК-035-Кассета 03-12). Нумерация тактов в музыкальных примерах соответствует нумерации в прил. 2.
} 
Таблица 1. Пропетый и произнесенный текст

Table 1. Sung and spoken text

\begin{tabular}{|l|l|}
\hline \multicolumn{1}{|c|}{ Пропетый «взвод» } & \multicolumn{1}{|c|}{ Произнесенный текст } \\
\hline Уз(а)ре́х(а) наро́ду м(а)но́га, & Узре́х мно́га наро́ду, взы́дуть на \\
Е в(а)зы́дя на Гору. & го́ру. \\
\hline
\end{tabular}

Таблица 2. Слогоритмическая организация напева

Table 2. Syllogorhythmic organization of the chant

\begin{tabular}{|l|l|l|l|l|l|l|l|l|l|l|}
\hline Слогопроизнесение & $\mathrm{y}$ & 3(a)- & pe & $\mathrm{x}(\mathrm{a})$ & на- & ро- & ду & м(a) & но- & га \\
\hline Число счетных единиц • & 13 & 3 & 27 & 3 & 27 & 15 & 13 & 3 & 32 & 23 \\
\hline
\end{tabular}

\begin{tabular}{|l|l|l|l|l|l|l|l|}
\hline Слогопроизнесение & Е & в(а)- & зы- & ду & на & го- & ру \\
\hline Число счетных единиц • & 10 & 2 & 16 & 39 & 41 & 74 & 4 \\
\hline
\end{tabular}

автономно. ${ }^{11}$ Словесное содержание теряется в развитых мелодических построениях и, таким образом, оказывается понятным лишь самим поющим: при этом на первый план выходит именно музыкальная составляющая псалма, наполненная собственным смыслом.

Песнопение характеризуется своеобразными принципами развития мелодики, осмысление которых позволит более точно выявить устойчивые тоны лада. Медленный темп, свойственный исполнению псалмов, в том числе «Узрех», позволяет четко и выпукло интонировать исполнительские приемы - специфический характер атаки звука, снятия дыхания. В результате их применения основной контур мелодии усложнился. Отметим наиболее характерные мелодические конструкции, основная функция которых идентична функции мелизмов и заключается в подчеркивании опорных тонов лада.

1. Движение от краткого нижнего неопорного тона на квинту или кварту вверх, к выделенному долготой опорному тону. Данный оборот, вероятно, по своему про-

\footnotetext{
11 Некоторые псалмы, например «Царь Давыд Осеевич», обнаруживают признаки тирадности, что свидетельствует о характерной для данного жанра сложности координации поэтического текста и напева.
}

исхождению связан с форшлагом, возникающим в результате специфической атаки звука (пример 1).

\section{Пример 1}

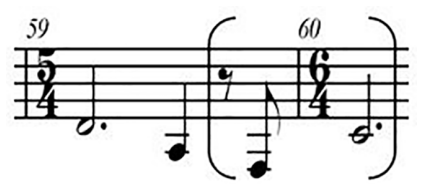

2. Ход вниз (на секунду, кварту и т. д.) или вверх (на секунду), связанный с пунктирным ритмом и сменой функции последнего тона с неопорного на опорный. Подобная интонационно-ритмическая конструкция обусловлена особенностями дыхания, является вариантом «сброса» звука (пример 2).

\section{Пример 2}

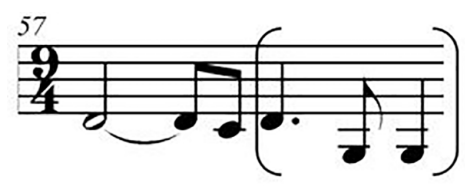

Вариант мелодического хода, связанного с певческим дыханием: движение от опорного тона на квинту вверх в конце строфы (пример 3) или на терцию вверх в середине напева (пример 4). 


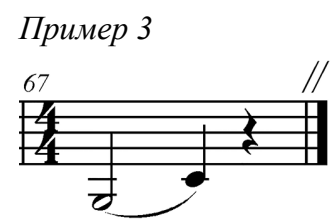

Пример 4

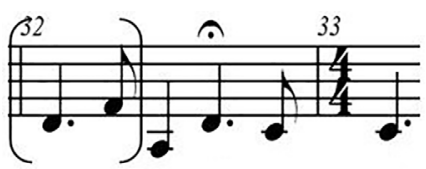

Напев «Узрех много народу» разворачивается в рамках широкообъемного диатонического звукоряда, в пределах которого реализуются две ладовых системы ангемитонной природы (трихорд в кварте и тетрахорд в квинте):

\section{Ладовая основа 1}

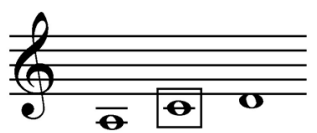

Ладовая основа 2

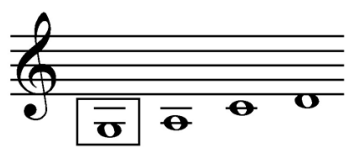

Ладовые конструкции ангемитонной природы встречаются в псалмах достаточно часто и обозначены Т. С. Рудиченко как характерный признак жанра (Rudichenko, 1990: 101). Нескольких побочных опорных тонов и один главный опорный тон (он отмечен квадратной скобкой) составляют основу простых ладовых основ напева «Узрех много народу». Представленные выше системы не равнозначны: преобладает первая. Важными композиционными единицами напева являются попевки, каждая из которых реализует оппозицию двух-трех опорных тонов. Опорные тоны выделяются долготой при помощи пунктирного ритма, а также орнаментируются мелодическими ходами «мелизматического» происхождения. Среди них выделяется попевка (a-d $\left.\mathrm{d}^{1} \mathrm{a}-\mathrm{c}^{1}\right)$, связанная с первой ладовой системой. Ее можно назвать основной: она варьируется и повторяется чаще других, что придает псалму интонационное единство.

Основная попевка

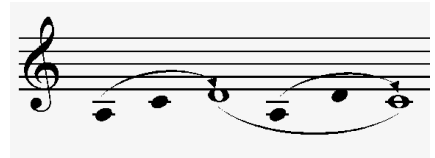

Преобладание принципа многократного повтора и варьирования основной попевки, возможно, связано с особенностями создания псалмов. В частности, А.К. Черткова, ссылаясь на комментарии духоборцев, писала, что мелодии псалмов сочиняет и импровизирует хор, развивая напев, «заведенный» одним из лучших певцов (Chertkova, 1910: 4) $)^{12}$.

Интервал кварты, в рамках которого развивается основная попевка псалма, имеет истоки в речевой интонации и обнаруживает параллели в русских песнях раннего историко-стилевого пласта. По мнению Б.В. Асафьева, «кварта и квинта как обращение кварты - довольно устойчивые "стабильные" интонационные вершины-"константы" голоса при повышенном эмоциональном тонусе речи (особенно в диалоге)» (Asaf'ev, 1971: 213). Согласно наблюдениям Ф.А. Рубцова, в русском фольклоре в зависимости от положения конечного устоя напевы, основанные на трихорде в кварте (как и в целом ангемитонные напевы), могут реализовывать лиро-повествовательную направленность (Rubcov, 1964: 28).

Примером ангемитонного напева повествовательной направленности (с ладовой основой fis'-a-h) может служить духовный стих о двух братьях - Лазаре и Абрамиче, записанный в с. Подсереднее Алексеевского р-на Белгородской обл. ${ }^{13}$

\footnotetext{
12 Следует отметить, что псалмы с подобной структурой (например, «Господи, Боже мой») функционируют в традиции духоборцев наряду с диатоническими напевами, мелодика «взводов» которых развивается динамично, и интонационные повторы не играют ведущей формообразующей роли.

13 Первыми духоборцами были выходцы из южных губерний Российской империи, в том числе из Тамбовской, Воронежской, Белгородской.
} 

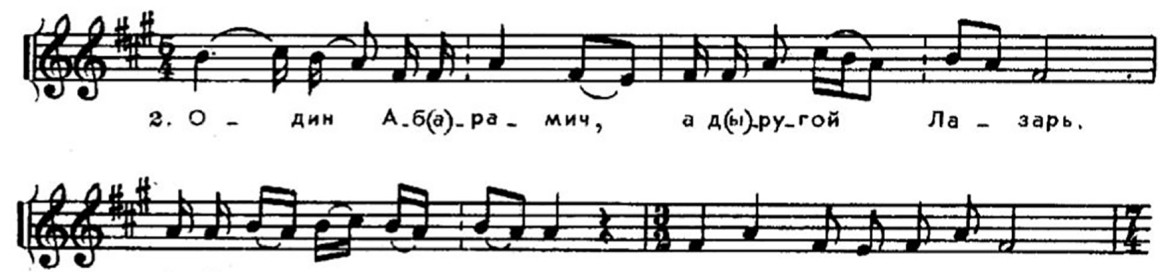

3. А_б(а).ра_мич бо-га_тый, а Ла_за_рь бе_д(а)_най.

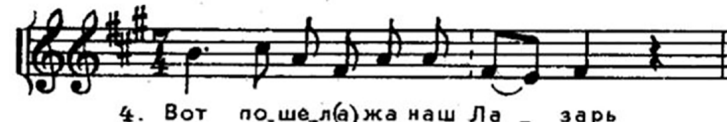

4. Bor по_ше_л(a)жа наш ла_ зарь

Вторая ладовая система напева «Узрех много народу» опирается на комплекс из двух попевок, которые выполняют функцию каданса, утверждающего главный опорный тон новой ладовой системы (смена главной опоры $\mathrm{c}^{1}$ на g).

\section{Кадансовые попевки}

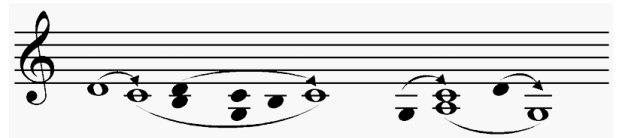

Таким образом, сложноладовая организация всего напева строится на сопоставлении двух простых ладовых систем ангемитонной структуры. Как отмечает Ф.А. Рубцов: «Соединение в одном напеве нескольких музыкальных фраз различной структуры вызывается сложностью и многогранностью музыкального содержания, не укладывающегося в эмоционально-смысловые рамки одной, начальной интонации» (Rubcov, 1964: 76). Сложноладовые структуры характерны для народных напевов, прежде всего лирических песен, повествовательного характера (примером может быть широко известный песенный тип «Горы Воробьевские»).

\section{Выводы}

Анализ псалма «Узрех много народу» и его сравнительная оценка позволяют обозначить важнейшие признаки жанра:

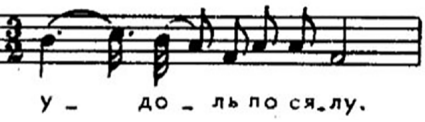

- псалмы представляют собой сакральные тексты и напевы, которые неразрывно связаны с религиозными обрядами;

- тексты Псалтири Царя Давида не являются единственным источником духоборческих псалмов. Наравне с ними в «Животную книгу» (как собрание текстов псалмов) входят духовные стихи, собственные духоборческие сочинения и т. Д. Еще одним источников поэтических текстов стало православное богослужение, откуда, вероятно, еще на раннем этапе развития секты был заимствован текст, содержащий «девять блаженств евангельских»;

- различные по происхождению (и часто по форме) тексты обретают стилевое единство в музыкальном воплощении: напевы псалмов доминируют над текстом и наделены собственным семантическим содержанием. Данное свойство подтверждается также тем, что во многих псалмах поэтический текст распевается частично и его содержание не раскрывается в полной мере;

- ряд напевов, включая псалом «Узрех», опирается на многократный повтор и варьирование одного интонационноритмического построения (попевки), составляя масштабный «взвод». В зависимости от протяженности поэтического текста количество повторов может варьироваться, в связи с чем границы строфы могут быть подвижными;

- музыкальные «повторы» в напевах псалмов (попевки, полустрофы) соотносят- 
ся со сквозным развитием поэтического текста, словесные повторы не характерны;

- каждому слогу текста соответствует мелодическая фраза / распев (несколько нот длительностью от трех четвертей до семидесяти). Таким образом, наличие слогораспевов - характерная черта стиля;

- развитая мелодика некоторых псалмов обнаруживает ангемитонную природу ладовых основ ${ }^{14}$, нередко имеет сложноладовую организацию.

14 В духоборческих традициях есть и диатонические напевы псалмов, ладовое строение которых требует отдельного исследования.
Несмотря на близость интонационноладового строения народным песням, вопрос генезиса псалмов остается открытым. В перспективе, в поисках истоков духоборческих псалмов необходимо обратиться к старообрядческим церковным песнопениям. Также следует рассмотреть возможные параллели с религиозными напевами общин меннонитов и гуттеритов, проживавших неподалеку от духоборцев в Таврической губернии и оказавших заметное влияние на традиционную культуру русской секты (Inikova, 1994).

\section{Список литературы / References}

Asaf'ev, B.V. (1971). Muzykal'naya forma kak process [Musical form as a process]. Leningrad, Muzyka. 376 p.

Bonch-Bruevich, V.D. (1909). Zhivotnaya kniga duhoborcev [Living Book of the doukhobors]. SaintPetersburg. 327 p.

Chertkova, A.K. (1910). Chto poyut russkie sektanty: sbornik sektantskih napevov s tekstom slov. Vyp. I: «Psalmy $i$ stishki» duhoborcev. [What Russian sectarians sing: A collection of sectarian chants with the text of words. Issue I: «Psalmy i stishki» of the doukhobors]. Moscow, Izdanie P. Yurgensona. $26 \mathrm{p}$.

Inikova, S.A. (1994). Istoriya i simvolika duhoborcheskogo kostyuma [History and symbolism of the costume of the doukhobors]. In Zhivaya starina [Living antiquity]. 1, 29-36.

Inikova, S.A. (2018). Religiozno-dogmaticheskaya sostavlyayushchaya v sovremennom pohoronnom obryade duhoborcev s. Gorelovka (Gruziya) [Dogmatic religious component in the modern funeral ceremony of the doukhobors S. Gorelovka (Georgia)]. In Zhizn' i nauchnyj put' ehtnografa. Materialy chtenij pamyati I. V. Vlasovoj [Life and scientific career of the ethnographer. The materials of readings in memory of I. V. Vlasova]. Moscow, IEHA RAN. 324-336.

Inikova, S.A. (1997). Tambovskie duhoborcy v 60-e gody XVIII veka [Tambov Dukhobors in the 60s of the XVIII century]. In Vestnik TGU. 1, 39-53.

Kashkin, A.S. (2010). Ustav pravoslavnogo bogosluzheniya [Charter of Orthodox worship]. Saratov, Izd-vo Saratovskoj eparhii. 687 p.

Kosyh, A.V. (2018). Bogomoleniya duhoborcev: vzaimosvyaz' s hristianskoj kul'turoj [The worship service of the doukhobors: the relationship with the Christian culture]. In Aktual'nye voprosy sovremennogo bogosloviya i cerkovnoj nauki: sbornik dokladov [Topical issues of modern theology and Church science: collection of reports]. Saint-Petersburg, Izdatel'stvo SPbPDA. 129-134.

Linyova, E. E. (2002). Muzykal'naya poezdka na Kavkaz [Musical trip to the Caucasus]. In Po sledam E. E. Linyovoj: sbornik nauchnyh statej [In the footsteps of E. E. Lineva: collection of scientific articles]. Vologda, Oblastnoj nauchnometodicheskij centr kul'tury i povysheniya kvalifikacii. 16-30.

Rubcov, F.A. (1965). Osnovy ladovogo stroeniya russkih narodnyh pesen [The modal basis of the structure of Russian folk songs]. Leningrad, Muzyka. 96 p.

Rudichenko, T.S. (1990). «Psalmy» kak zhanr duhoborskoj tradicii [«Psalms» as a genre of Dukhobor tradition]. In Otechestvennaya kul'tura XX veka i duhovnaya muzyka: tezisy dokladov Vsesoyuznoj nauchno-prakticheskoj konferencii [Russian culture of the XX century and spiritual music: abstracts of the all-Union scientific and practical conference]. Rostov-on-Don, 100-102.

Schurov, V.M. (1995). Pesni Usyordskoj storony [Songs of «Usyordskij» region]. Moscow, Kompozitor. $360 \mathrm{p}$. 
Trebnik (2008). [Prayer book]. Moscow, Izdatel'skij sovet RPC. 608 p.

Zernina, A.V. (2017). Pevcheskaya tradiciya duhoborov Rostovskoj oblasti: konfessional'nyj i regional'nyj aspekty [The singing tradition of the doukhobors of Rostov region: confessional and regional perspectives]. Dissertaciya na soiskanie uchenoj stepeni kandidata iskusstvovedeniya: 17.00.02. Muzykal'noe iskusstvo [PhD Thesis in Music]. Rostov-na-Donu, Rostovskaya gosudarstvennaya konservatoriya im. S. V. Rahmaninova. 251 p. 
Приложение 1

Архив ФЭЦ СПбГК. ОЦФ № 276-001-02-33. Записала А. В. Косых от Гончаровой Агафьи Михайловны 1911 г. р.

Узре́х мно́га народу, взы́дуть на гору. Ше́дшие Я̈во́ приступили к Няму́ все ученики Яво́. Отве́рзт Ису́с уста Свои, уча́ша их г̆лаго́леть к ним:

Блаже́нные ни́шщие духом, яко у тех есть Царство Небесное. Помяни нас, Господи, когда прииддешь во Царствие Своё.

Блаженные пла́чушщии, яко те во век уте́шутся. Помяни нас, Господи, когда прии́дешь во Царствие Своё.

Блаженные а́лчушшие и жа́ждушшие, яко те во век насытются. Помяни нас, Господи, когда приидешь во Царствие Своё.

Блаженные кроткие, яко те насле́дуют землю. Помяни нас, Господи, когда приидешь во Царствие Своё.

Блаженные ми́лосливые, яко те помилованы будут. Помяни нас, Господи, когда прии́дшь во Царствие Своё.

Блаженные чистые сердцем, яко те Бог̆а уззют. Помяни нас, Господи, когда прии́дешь во Царствие Своё.

Блаженные миротворцы, яко те сына́ми Божьими наряку́тся. Помяни нас, Господи, когда прииддешь во Царствие Своё.

Блаженные изг̆на́нные, яко тем есть Царство Небесное. Помяни нас, Господи, когда прии́дешь во Царствие Своё.

Блаженные, когда поно́сють на вас, жену́ть и ряку́ть, всяк зол г̆лаг̆о́лють, на вас лжу́ть. А вы мене́ ради радуйтесь, веселитесь, яко мно́̆о мно́жества и мзды ва́ша на небесех.

Бог̆у нашему слава. 
Приложение $2^{15}$

Архив ФЭЦ СПбГК ОФК-035-Кассета 03-12.

2. Богдановка Богдановского р-на Грузинской ССР.

Записала С. Е. Никитина от М. С. Юрицыной 1922 г. р.
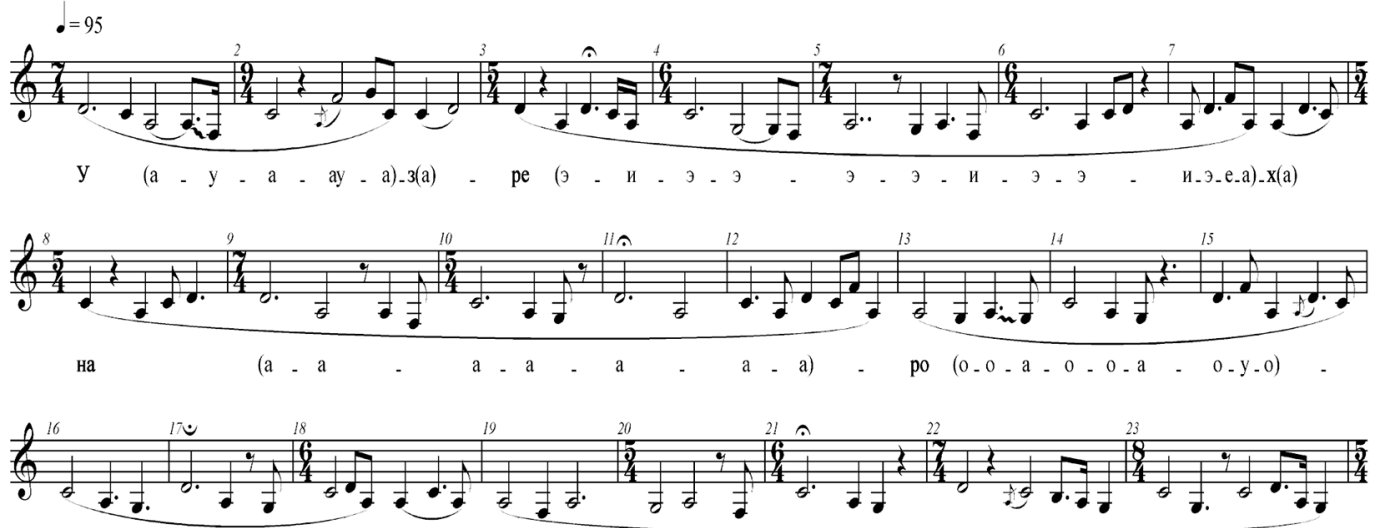

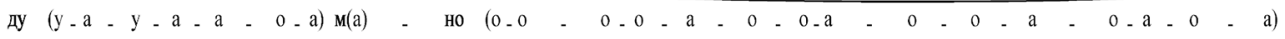

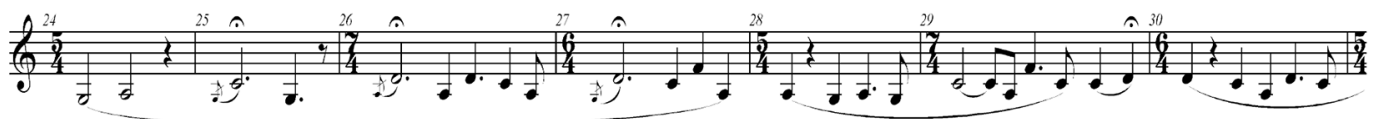

ŕa

$(y a-a-y a-a-y a)$

е (и э - э - е) в(а) - зы (ы - э э.

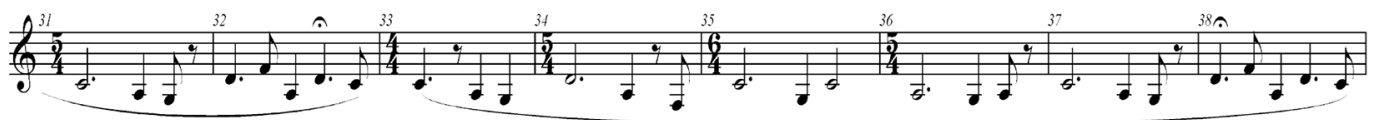

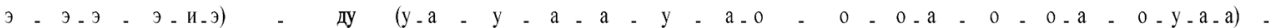

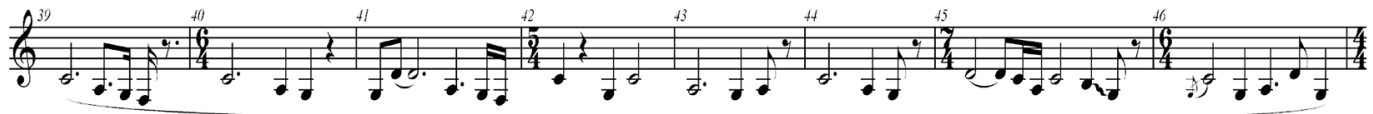

ду (a - $0-0 . a-a-0-0-a-0-0.0-0-0-a-0-a-0-0-0 . a-0 . a-0-a)$
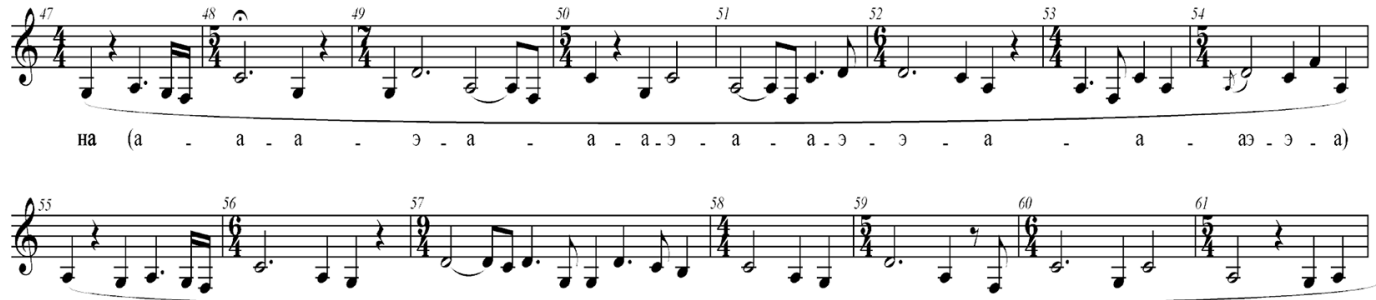

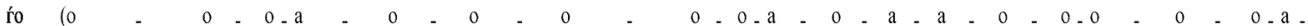

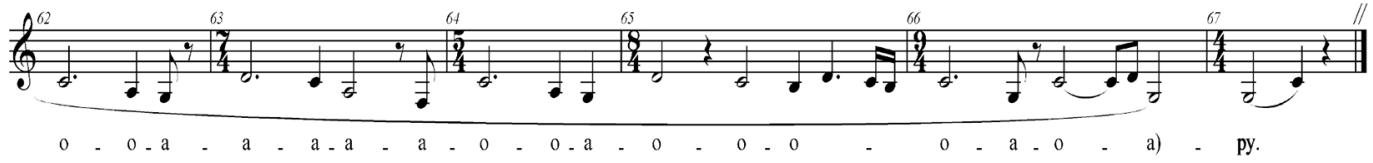

15 На аудиозаписи псалом звучит на большую терцию ниже. При сопоставлении данного напева с ансамблевым вариантом (Архив ФЭЦ СПбГК ОФК-035-Кассета 02-13) выявлено, что мелодия в тактах 33-38, 40 является ошибкой (повтором), данные фрагменты не учитываются при анализе песнопения. 